\title{
The Variations in Verb-Preposition Combinations in the GloWbE Corpus and its Usage in Informal Englishes
}

\author{
Kazi Amzad Hossain \\ University of Asia Pacific, Dhaka, Bangladesh \\ amzad26@uap-bd.edu
}

\section{ARTICLE HISTORY}

Received : 2021-02-07

Revised : 2021-04-13

Accepted : 2021-04-18

\section{KEYWORDS}

Corpus data

Verb-preposition variations

Inner circle and outer circle countries Frequency

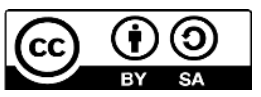

\begin{abstract}
This paper is based on the Corpus of Global Web-based English (GloWbE) compiled by Mark Davies in 2013. The GloWbE corpus consists of web data from 20 different English speaking countries. This research is constructed on the GloWbE corpus to investigate the variations in certain verb-preposition combinations in informal Englishes. As the corpus is divided into two sections, such as - general and blog, this study is based on the blog section to compare web data from two inner-circle countries such as The USA and Great Britain and two outer-circle countries such as - India and Bangladesh. The reason for selecting the blog is that, in the GloWbE corpus, the blog section consists of informal data, whereas the general section consists of formal data. It is to be noted that the inner-circle countries use English as their native tongue, whereas the outer-circle countries use English as their second or foreign language. This paper argues that the verb-preposition combinations or prepositional verbs vary in their frequency and meaning in the countries mentioned above. This paper investigates the following five prepositional verbs from The Cambridge Grammar of the English Language proposed by Huddleston and Pullum in 2002- come up with, look out for, put up with, stand up to, and get along with in the GloWbE corpus to prove that the frequency and meaning of these phrases vary from country to country based on social, cultural and political contexts as seen in the results. The investigation shows the trends of the above five prepositional verbs in the four countries explicitly.
\end{abstract}

\section{Introduction}

"The word corpus is Latin for the body (plural corpora). In linguistics, a corpus is a collection of texts (a 'body' of language) stored in an electronic database. Corpora are usually large bodies of machine-readable text containing thousands or millions of words" (McEnery, Hardie and Baker 2006, p. 48). Kennedy (1998, p. 143) observes, "[...] corpus-based studies of prepositions reveal that many of them frequently occur in recurring collocations and that systematic analysis of the phrases which prepositions form part of reveals a variety of different semantic roles". The foundation of this paper is based on Davies (2013), Davies (2015), Davies and Fuchs (2015) and Davies (2020). About the GloWbE corpus, Davies (2020) reports, "at the most basic level, researchers can see the frequency of a word or phrase in all 20 countries [...]". He also discusses the different functions of 'List', 'Chart', 'Collocates', 'Context', and 'KWIC' (meaning - Key Word In
Context) in the GloWbE corpus in EnglishCorpora.org: a guided tour (cf. 2020).

"Language is inherently variable, both across time (diachronically) and at any specific point in time (synchronically)" (Krug \& Schlueter 2013, p. 01). "Computer corpus-based studies of variation in English became possible with the availability of the Brown Corpus from 1964" (Kennedy, 1998, p. 181). Later, due to the development of electronic technology, more and more corpora were built to research different aspects of various languages. Subsequently, the Corpus of Global Web-based English (GloWbE) was compiled and released by Mark Davies in 2013 (cf. Davies, 2015). "GloWbE is based on 1.9 billion words in 1.8 million web pages from 20 different English-speaking countries" (Davies and Fuchs 2015, p. 01). According to Davies and Fuchs (2015, p. 01), "Because of its large size, its architecture and interface, the corpus can be used to examine many types of variation among dialects, 
which might not be possible with other corpora [...]". This is the prime reason that the GloWbE corpus has been selected to investigate the variations in verbpreposition combinations in informal Englishes. As "the texts in the corpus consist of informal blogs (about $60 \%$ of the corpus) and other web-based materials, such as newspapers, magazines, company websites, and so on" (Davies, 2015), this paper focused on 'Blog' category to analyze the variations. Moreover, as the GloWbE corpus contains texts from "Six Inner Circle and 14 Outer Circle countries" (Davies and Fuchs 2015, p. 02), for this study, two inner-circle countries - The USA and Great Britain and two outer-circle countries - India and Bangladesh have been selected to compare the data.

The reason for selecting these countries are manifolds - firstly, the inner-circle countries use English as their primary language or native language, whereas the outer-circle countries use English as their second or foreign language (cf. Kachru 1985, p.12); secondly, I assume, that The USA and Great Britain have a large number of data available to compare with the data from India and Bangladesh; thirdly, I also assume that there are socio-cultural differences among the inner circle and the outer-circle countries which may also indicate regional language variation. I argue that the verb-preposition combinations or prepositional verbs vary in their frequency and meaning in the countries above. This paper examines the following prepositional verbs from The Cambridge Grammar of the English Language by Huddleston and Pullum (2002, p. 287) - come up with, look out for, put up with, stand up to, and get along with in the GloWbE corpus to prove that the frequency and meaning of these phrases vary from country to country.

In this paper, I analyzed the verb-preposition combinations concerning the GloWbE corpus. To support my arguments, I used related quotations, charts, tables and figures with proper citations. I defined the related topics and described the background of corpora to set the ground for the research. Later, I examined the five verbs with examples of the first ten hits in the four countries. Finally, I discussed the results of the corpus data to demonstrate which countries have more or less usage of the specified verb-preposition combinations.

\section{Literature Review}

Baldwin (cf. 2005, p. 09) worked with corpus data to find out prepositional verbs and gave a list of '100 most-frequent verbs' and ' 10 most-frequent transitive prepositions' separately, from the written section of the British National Corpus (BNC). However, he did not list any prepositional phrases or idioms in his study. Gardner and Davies (cf. 2007, p. 358-359) also pointed out the 'Top 100 Phrasal Verb Lemmas in BNC'. Liu (cf. 2011) studied the Corpus of Contemporary American English (COCA) and the British National Corpus (BNC) to find out the most frequent English phrasal verbs and found that 20 out of 30 phrasal verbs are "more common in American English" (p. 671), however, he did not specify any prepositional verbs in his study. Unlike them, I will look into the GloWbE corpus, which is relatively new compared to the $\mathrm{BNC}$, for my selected verbpreposition combinations. In this regard, I have discussed the definitions of a phrasal verb, idiom and prepositional verb below.

Further, "Phrasal verbs also called (idiomatic) multi-word verbs, consist of a verb, an adverb (adverbial particle) and a preposition. Some verbs are called prepositional verbs since they consist of a verb and a preposition" (Ostyn-Rudzka 2003, p. 01). According to Huddleston and Pullum (2002), "The term 'phrasal verb' implies that the combinations concerned form syntactic constituents belonging to the category verb" (2002, p. 274). Besides, phrasal verbs can have multiple, context-sensitive meanings (cf. Gardner and Davies 2007, p. 345). In Dagut and Laufer's (1985) study of English phrasal verbs on Israeli students, they noticed that, out of literal, figurative and completive phrasal verbs, students used figurative phrasal verbs the least (cf. Dagut and Laufer 1985: 74-77), which may indicate that, "the figurative, or idiomatic, phrasal verbs were considered semantically more difficult than other types of phrasal verbs" (Liao and Fukuya 2004: 197). Similarly, it will be interesting to see the frequency of idiomatic verbpreposition combinations in GloWbE corpus.

To approach the further discussion on multi-word verbs, idioms needed to be defined. "An idiom is an expression larger than a word whose meaning cannot be systematically derived from meanings that the parts have when used independently of each other" (Huddleston and Pullum 2002, p. 273). In a verbpreposition combination, Huddleston and Pullum classified preposition as (i) specified and (ii) unspecified and grouped specified preposition in two types - mobile preposition and fixed preposition. Verb and a specified proposition create a verbal idiom, and a fixed verb and preposition combination are called a fossilized combination (cf. Huddleston and Pullum 2002, p. 275, 277).

Moreover, they also pointed out, "[...] the term 'prepositional verb' applies to the sequence of verb + preposition, [...]", and "prepositional verbs $[. .$.$] are$ those which select a PP [Prepositional Phrase] 


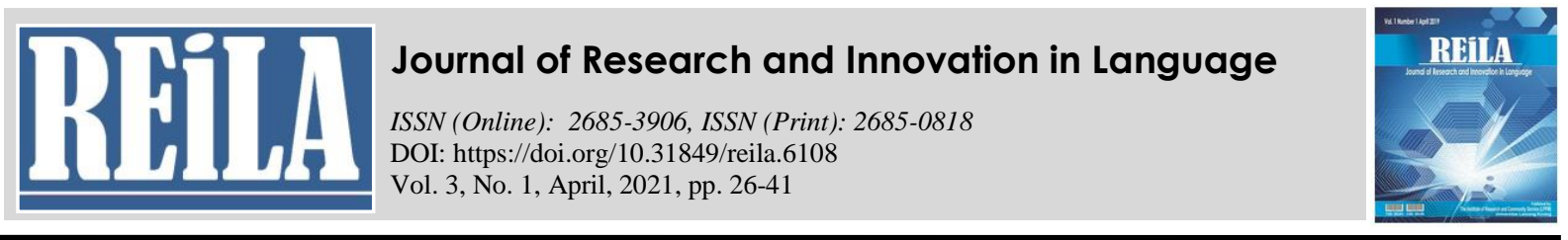

complement containing a specified preposition together with its complement" (2002, p.274).

Furthermore, they provided a structural list of six verb-preposition combinations, given below:

Table 2.1 Prepositional verbs structure

\begin{tabular}{cll}
\hline Sl. no. & \multicolumn{1}{c}{ Prepositional verbs structure } & Examples \\
\hline 1 & verb $-[\mathrm{prep}+\mathrm{O}]$ & I referred [to her book]. \\
2 & verb $-\mathrm{O}-[\mathrm{prep}+\mathrm{O}]$ & I intended it [for Kim $].$ \\
3 & verb $-[\mathrm{prep}+\mathrm{O}]-[\mathrm{prep}+\mathrm{O}]$ & He looked $[$ to her $][$ for guidance $]$. \\
4 & verb $-[\mathrm{prep}+\mathrm{PC}]$ & It counts [as too short $].$ \\
5 & verb $-\mathrm{O}-[\mathrm{prep}+\mathrm{PC}]$ & They regard it [as successful]. \\
6 & verb $-[\mathrm{prep}+\mathrm{O}]-[\mathrm{prep}+\mathrm{PC}]$ & I think [of it $]$ [as indispensable $].$
\end{tabular}

(Adapted from Huddleston and Pullum: 2002, p.277)

Prep in chart one means preposition, $\mathrm{O}$ is for Object, and PC means Predicative Complement. The chart explains the structure of prepositional verbs. As it can be noticed that the verb is always in the initial position, and it can be followed by either prepositions or objects, while the predicative complement only takes prepositions before them. From the chart, it is clear that it be a prepositional verb. The proposition need not be always in the immediate position after the verb.

\section{Method}

The methodology in this paper follows a quantitative approach to find out the real-world usage of the five verb-preposition combinations. The data have been collected from the GloWbE corpus, and by explicitly using the 'list', 'chart' and 'context' functions of the website, the examples have been narrowed down. As Davies compiled the corpus in 2013, the examples have not been changed to date. As a result, the usage of the five verb-preposition combinations could be extracted from the online database. First, I looked into the frequency of the verb-preposition combinations of each of the five verbs. Then I compared the frequencies among the four countries to see the variation. After that, I examined whether some prepositional verbs occur more or less in a specific context. As Davies (2020, p. 05) observes, "words do not occur in isolation, and learners need to understand the patterns that a given the word takes".

\section{Corpus Data and Results}

For my research, as I have chosen four countries, two from the inner circle (The USA and Great Britain) and two from the outer circle (India and Bangladesh), I would like to begin by showing the number of web sites and web pages in the 'Only Blogs' section of those countries in the GloWbE corpus.

Table 4.1 Adapted from Corpus of Global Web-Based English web site by Davies (2013)

\begin{tabular}{lcccc}
\hline \multirow{2}{*}{ Country } & Code & & \multicolumn{2}{c}{ (Only) Blogs } \\
\cline { 3 - 5 } & & Web sites & Web pages & Words \\
\hline United States & US & 48,116 & 106,385 & $133,061,093$ \\
\hline Great Britain & GB & 35,229 & 149,413 & $131,671,002$ \\
\hline India & IN & 9,289 & 37,156 & $28,310,511$ \\
\hline Bangladesh & BD & 2,332 & 14,246 & $10,922,869$ \\
\hline
\end{tabular}

From the table above, it is clear that the innercircle countries have far more web sites and web pages than the outer-circle countries. Therefore, more data will be available to investigate in the US and GB than in the other two countries.
Now, if I look into the five prepositional verbs in all the countries (Figure 4.1) in the GloWbE, it is evident that all these verbs occur more in the general section of the corpus than in the blog section. It is 
logical to assume that, as the general section has more data, the verbs occur more frequently in that section.

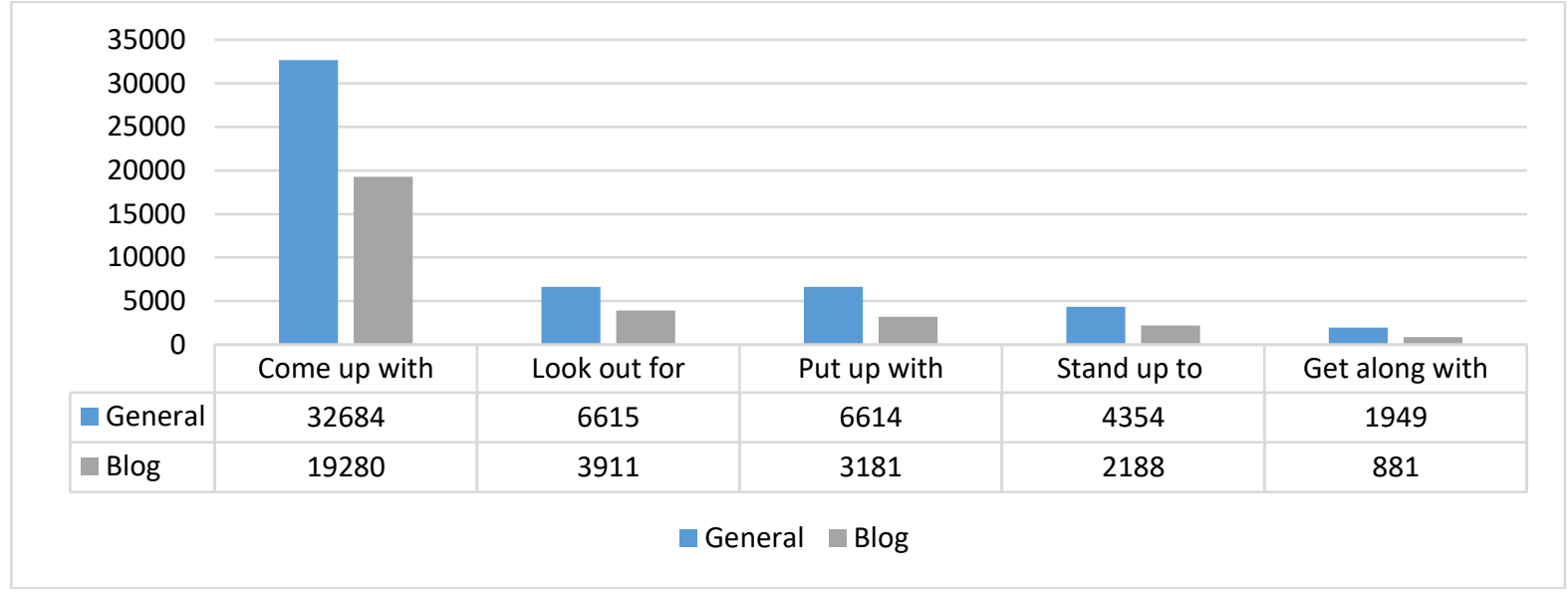

Figure 4.1 Total raw frequency of the five prepositional verbs in general and in the blog section of the GloWbE corpus in 20 countries

Now, if I narrow down my search and look for each of the prepositional verbs in the blog section in the four countries, the verb (1) come up with shows the following trends as in Table 4.2.

Table 4.2 Raw frequency and normalized frequency (NF) of the prepositional verb come up with in the blog section with the corpus size in a million words in the four countries

\begin{tabular}{lccccc}
\hline \multicolumn{1}{c}{ Section } & Total in 20 & & GB & BS & BN \\
\hline Frequency (raw) & 19280 & 5193 & 4196 & 1077 \\
Words (Million) & 1900 & 386.8 & 387.6 & 96.4 & 39.5 \\
(3) Per Million (NF) & 10.15 & 13.43 & 10.83 & 11.17 \\
\hline
\end{tabular}

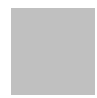

Out of the total raw frequency of 19280 in 20 countries, it occurs more in the US English than in GB, IN or BD English. From table 4.2 (second row), it can also be noticed that the size of the corpus varies from country to country. Out of 1900 million words, the US has 386.8 million, GB has 387.6 million, IN has 96.4 million, and BD has 39.5 million words in total in the blog section. The third row indicates the normalized frequency (NF) per million words. The formula ${ }^{1}$ to get the normalized frequency $(\mathrm{NF})$ is -

$N F($ per million words $)=\frac{\text { Raw frequency }}{\text { Corpus Size }} \times 1000,000$
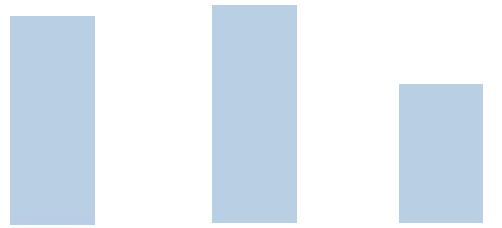

The data from table 4.2 shows, across the four varieties of English, after the normalized frequency, come up with is more frequent in the US and GB English, i.e. in the inner-circle countries, than in IN and BD. Furthermore, if I use the 'Collocates' function of the GloWbE corpus as in figure 4.2 (next page), and select the 'blog' section for the phrase come up with, to search for two words before and two words after, I find a list of words (figure 4.3) that 'hangs out with' (Davies 2020, p. 06) the phrase come up

with.

\footnotetext{
${ }^{1}$ From https://www.youtube.com/watch?v=9s7cJY8EIrE, video title: Sociolinguistics and Corpus Linguistics - Compare a language across different regions and speakers Yassine Iabdounane.
} 


\begin{tabular}{l} 
Journal of Research and Innovation in Language \\
$\begin{array}{l}\text { ISSN (Online): 2685-3906, ISSN (Print): 2685-0818 } \\
\text { DOI: https://doi.org/10.31849/reila.6108 } \\
\text { Vol. 3, No. 1, April, 2021, pp. 26-41 }\end{array}$ \\
\hline
\end{tabular}

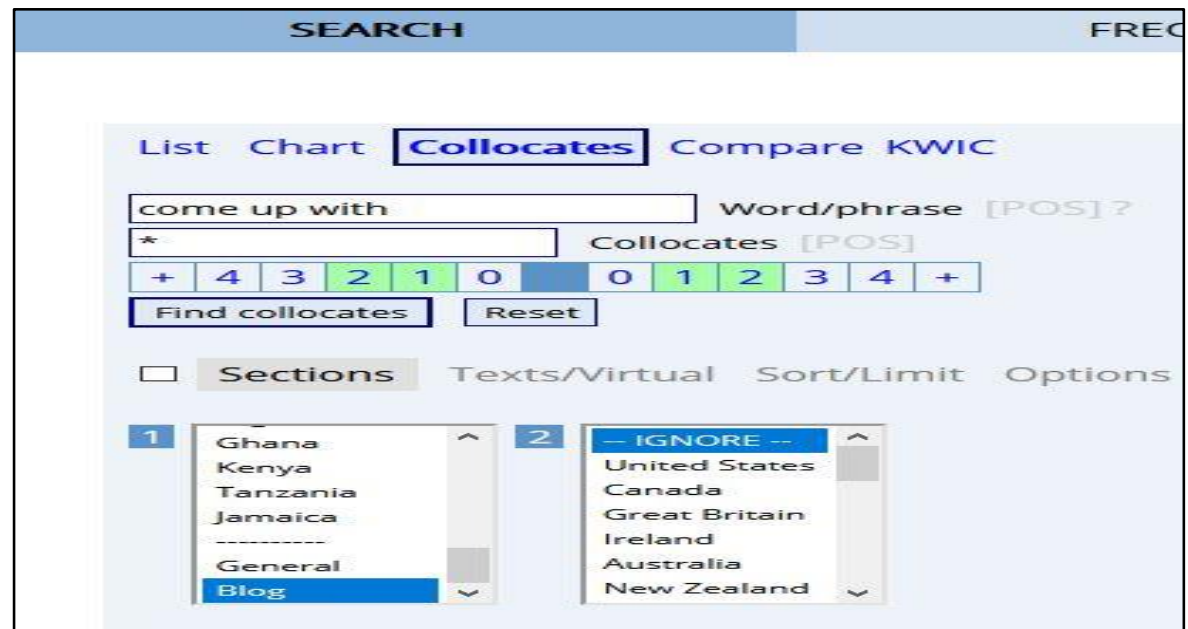

Figure 4.2 Searching 'collocates' function in the GloWbE corpus for the prepositional verb come up with

\begin{tabular}{|c|c|c|c|c|c|c|c|}
\hline HELP & $\square$ & \begin{tabular}{|l|} 
CONTEXT \\
\end{tabular} & FREQ & ALL & $\%$ & MI & \\
\hline 1 & $\square$ & COULD & 928 & 750427 & 0.12 & 3.23 & 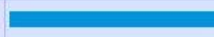 \\
\hline 2 & $\square$ & ABLE & 340 & 261010 & 0.13 & 3.30 & 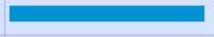 \\
\hline 3 & $\square$ & TRYING & 298 & 170164 & 0.18 & 3.73 & - \\
\hline 4 & $\square$ & TRY & 234 & 205812 & 0.11 & 3.11 & 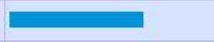 \\
\hline 5 & $\square$ & UNABLE & 54 & 27876 & 0.19 & 3.87 & - \\
\hline 6 & $\square$ & STRUGGLING & 44 & 20243 & 0.22 & 4.04 & - \\
\hline 7 & $\square$ & DESIGNERS & 37 & 14501 & 0.26 & 4.27 & - \\
\hline 8 & $\square$ & DEVELOPERS & 28 & 20692 & 0.14 & 3.36 & - \\
\hline 9 & $\square$ & IMAGINATION & 17 & 12722 & 0.13 & 3.34 & - \\
\hline 10 & $\square$ & COLLABORATORS & 15 & 1361 & 1.10 & 6.38 & I \\
\hline
\end{tabular}

Figure 4.3 List of the first ten most frequent words that collocates with the verb come up with in the blog section

The drawback of this search is that figure 4.3 shows data from all the twenty countries listed in the GloWbE corpus. As it will be a time-consuming task to separate four specific countries for this function, I left it for another research. However, as Davies (2020, p. 06) points out, "Collocates (nearby words) can provide beneficial insight into the meaning and usage of a word or phrase" and "also move beyond strict 'word meaning' to show 'what we are saying' about different topics" (2020, p.08). I looked into the chart function as in figure 4.4 to investigate the first ten sentences or hits in each of the four countries that I am discussing.

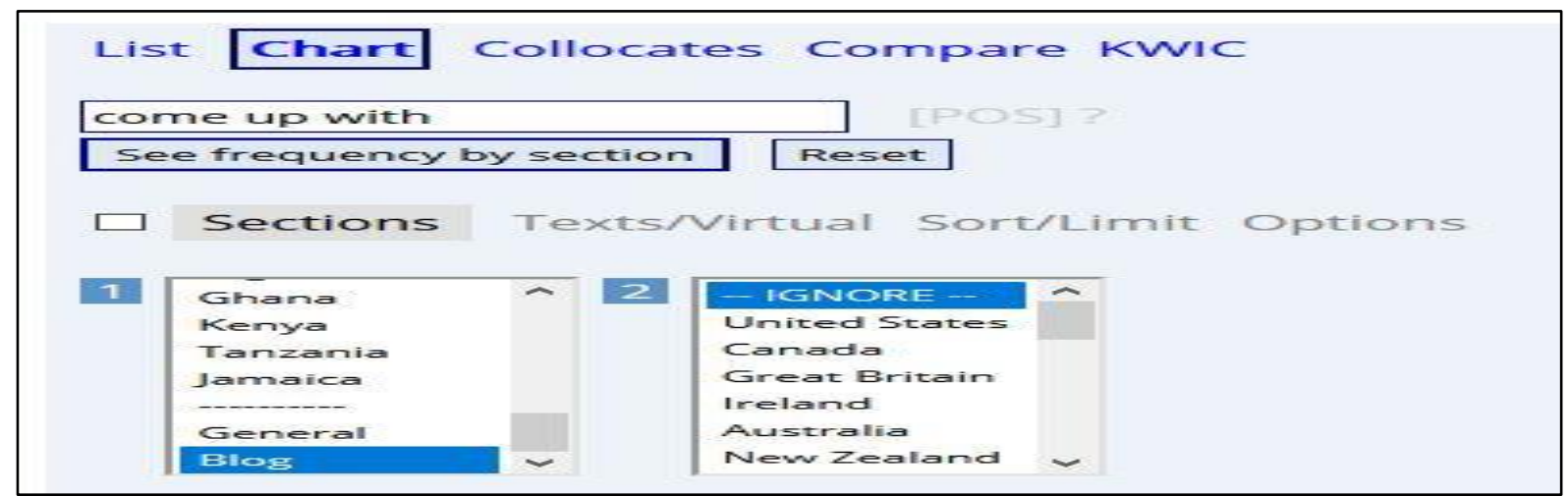

Figure 4.4 Using chart function to look into the first ten sentences used in the four countries.

The search result (first ten hits) for the US (figure 4.5) shows that the combination was primarily used on blogs and in online newspapers. Also, the context was primarily political. 


\begin{tabular}{|c|c|c|c|c|c|}
\hline \multicolumn{6}{|c|}{$\begin{array}{l}\text { SECTION: United States }(5,193) \\
\text { FIND SAMPLE: } 1002000 \underline{500} \underline{1000} \\
\text { PAGE: } \ll\langle 1 / 52\rangle \gg\end{array}$} \\
\hline \multicolumn{3}{|c|}{ CLICK FOR MORE CONTEXT } & $\square$ [?] & [?] SAVE LIST CHOOSE LIST $\longrightarrow$ CREATE NEW LIST & [?] \\
\hline 1 & USB & ....amylou.wordpress.com & $A B C$ & \multicolumn{2}{|c|}{ at the time I was 18 and it was so groundbreaking, no one had come up with such a unique concept -- of course reality television is $n$} \\
\hline 2 & USB & ...astroad.blogspot.com & $A B C$ & \multicolumn{2}{|c|}{ last year because it felt like it portrayed that she was the first person yo come up with all these gorgeous crafts... ok get off your ban } \\
\hline 3 & USB & ....astroad.blogspot.com & $A B C$ & \multicolumn{2}{|c|}{ the most inventive crafters I know... I'm looking forward to seeing what you come up with for that guest room Wendz! \# Yep - a lot of } \\
\hline 4 & USB & 21210.co & $A B C$ & \multicolumn{2}{|c|}{ Halloween, stars and stripes for the fourth of July, any pattern that you come up with is alright. But for now, lets work with the Christ } \\
\hline 5 & USB & 21stcenturywire.com & $A B C$ & \multicolumn{2}{|c|}{ I massive resources to get to the bottom of the paedophile rings, only to come up with one arrest... the Cambodian child harvester k } \\
\hline 6 & USB & 247wallst.com & $A B C$ & \multicolumn{2}{|c|}{ \#\#3149046 US Wants Other Governments To Come Up With More Cash, Which They May Not Have \# The US is calling } \\
\hline 7 & USB & 24ahead.com & $A B C$ & \multicolumn{2}{|c|}{ scheme? That appears to be the one-two punch they plan: the Senate will come up with something, then Bush will try to sell it to the } \\
\hline 8 & USB & 24ahead.com & $A B C$ & \multicolumn{2}{|c|}{ of the stated original version is here. \# In response, the Democrats have come up with their own version of the letter that they're der } \\
\hline 9 & USB & 24flinching.com & $A B C$ & \multicolumn{2}{|c|}{ what terror is, right? People who are shit-blind angry and repressed and will come up with creatively devastating ways to hurt people } \\
\hline 10 & USB & ...bananasadaysucks.com & $A B C$ & \multicolumn{2}{|c|}{ recommended daily allowance for dietary $n-3 / n-6$ fats right along with cholesterol. The WAPF will come up with some numbers thoug } \\
\hline
\end{tabular}

Figure 4.5 First ten instances of the use of come up with in US English in the blog section

Similarly, the search result (first ten hits) for GB shows that the verb come up with was used in informal contexts, not to describe any political news. The sense in which it is used is similar to the US English, which indicates 'bring forth' (WordNet Search - 3.1). In Indian English, the first ten hits on come up with primarily represent dialogues in either festival contexts or job contexts. However, while searching for detailed contexts, some links did not work. In the case of Bangladeshi English, the first ten hits point to banking websites, personal blogs and travel blogs. There was no political context, and from the banking sites, it seemed that the language in which come up with is used is more formal than the US and GB English.

Table 4.3 Raw frequency and normalized frequency (NF) of look out for in the blog section of the GloWbE corpus

\begin{tabular}{cccccc}
\hline Section & $\begin{array}{c}\text { Total in } 20 \\
\text { Countries }\end{array}$ & US & GB & IN & BD \\
\hline Frequency (raw) & 3911 & 451 & 1165 & 196 & 29 \\
Words (Million) & 1900 & 386.8 & 387.6 & 96.4 & 39.5 \\
Per Million (NF) & 2.06 & 1.17 & 3.01 & 2.03 & 0.73
\end{tabular}

The second verb-preposition combination I searched in GloWbE is look out for. Table 4.3 shows that the phrase look out for was more frequently used in GB and IN English than the US and BD English. As GB has the most significant corpus size $(387.6$ million), among the four countries, it has the highest number of raw frequency (1165). Normalized frequency is also the highest in GB English with 3.01 per million. Besides, it is evident from table 4.3 that one of the outer-circle countries, i.e. India, has higher usage (per million) of look out for compared to the inner circle country - the US.

P


Apart from this, I used the chart function in the GloWbE corpus to see the first ten example sentences with a look out for in it. The first ten hits for US English (figure 4.4) shows various examples from personal, business and sports blogs. The phrase look out has two senses in WordNet Search - 3.1 such as (1) to be vigilant, and (2) to protect someone's interests (cf. http://wordnetweb.princeton.edu), and in the examples, shows both the meaning senses in the US English. For example, in the second hit, look out for indicates to protect the interest of a person's brother, while in the eighth hit, the meaning is to be vigilant in case of autocrats' misuse of technology.

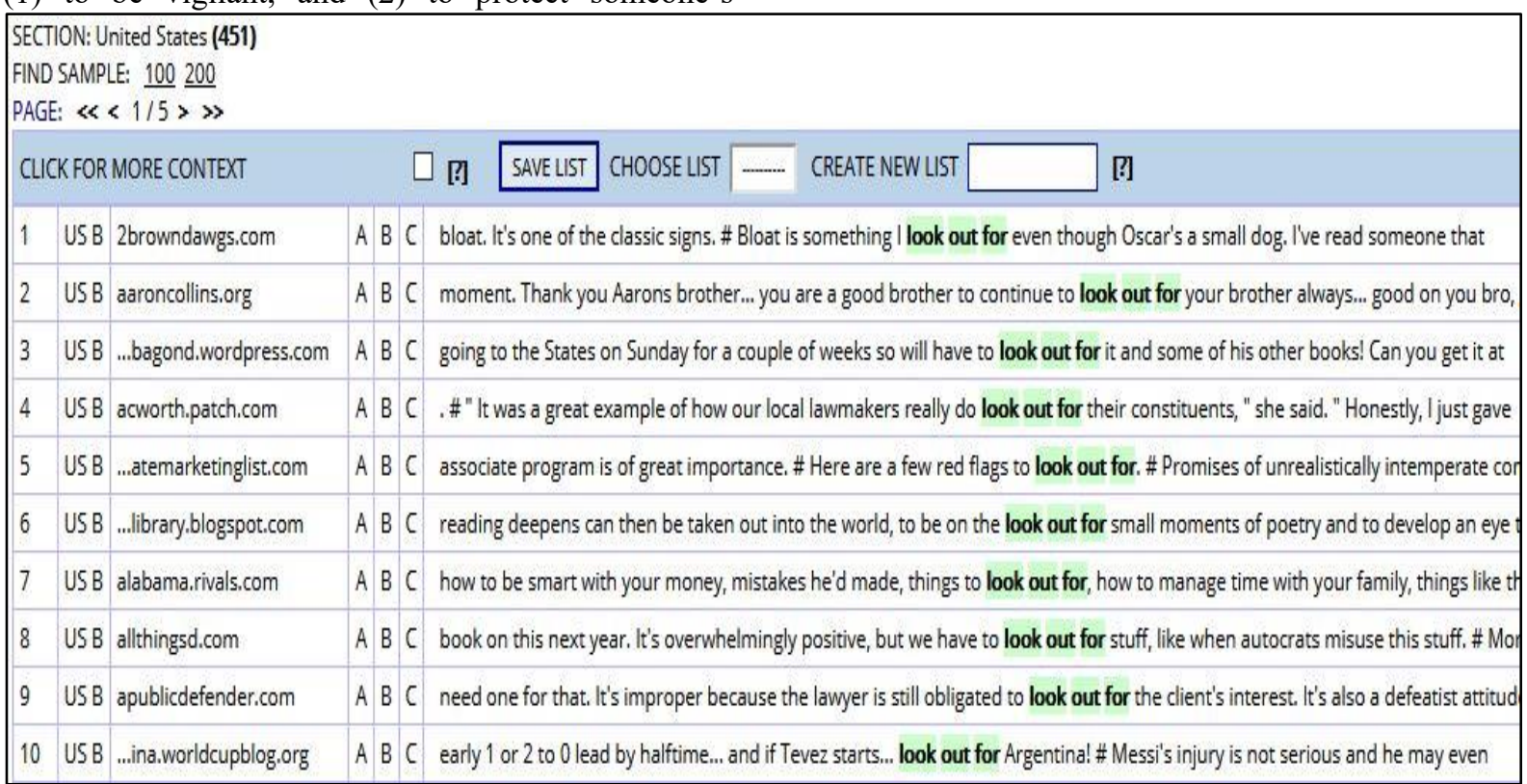

Figure 4.6 First ten examples of look out for in the US English in blog

However, the first ten hits in the search result for GB shows that mostly look out for were used to pay attention to something or search for something. Example sentences are from personal blogs, medical blogs and online magazines. In Indian English, the first ten hits using look out for are from personal blogs and websites and online photography magazine. The ordinary senses of the phrase are to protect a family's interest and search for something (figure 4.7).

\footnotetext{
SECTION: India (196)

FIND SAMPLE: $\underline{100}$

PAGE: $\ll<1 / 2 \gg \gg$

CLICK FOR MORE CONTEXT $\square$ [? SAVE LIST CHOOSE LIST - CREATE NEW LIST $\square$ [?]

1 IN B allinfographics,org $\quad A B C$ two began manufacturing and selling crystal meth. What started as a desperate attempt to look out for his family quickly transformed

2 IN B allinfographics.org A B C can now be benefited to someone who is in need of it. \# Continuously look out for various Coupon code website which provides nume

3 IN B ...le-search-engine.com A B C when I read stories like Gary Emanuel's, and I'm constantly on the look out for similar stories of the pay off of persistence and of never

4 IN B ...llywood.blogspot.com A B C \# Thanks for writing about " Listen Amaya ". I will be sure to look out for it on DVD. Farooque Shaikh was always stellar. The young lady

5 IN B betterphotography.in A B C of experts who can guide you about the geography, history and photo opportunities to look out for during the event. You need to ador

6 IN B blahandmore.com A B C to give your 100\% to it. Love your Job; And if not, look out for the one that you would

7 IN B blog.avagmah.com A B C make it cutting edge and industry relevant. This is something that the Corporates really look out for. \# If you are a working professiona

8 IN B bloginternshala.com A B C Also while carrying out my study, my field guide and I did keep a look out for the Red Panda, locally known as Thungmo, but elusive as

9 IN B blog,miteshashar,com A B C Enthusiastic Not to mention, this is something even conglomerates or bigger established firms would look out for, but is like a basic red

10 IN B ...g.simplyadvanced.net A B C and with Adwords. Anyway I am including this RSS to my email and can look out for much extra of your respective exciting content. Ma
} 
Figure 4.7 First ten hits of look out for in Indian English in the blog section.

In Bangladeshi English, however, there were only 29 example sentences, out of which I looked into the first ten hits. Figure 4.8 shows the first ten hits in BD
English, where most websites are personal blogs, except a university website (hit no. 10).

\begin{tabular}{|c|c|c|c|c|c|}
\hline \multicolumn{6}{|c|}{ SECTION: Bangladesh (29) (SHUFFLE) } \\
\hline \multicolumn{3}{|c|}{ CLICK FOR MORE CONTEXT } & & SAVE LST CHOOSE LIST $\longrightarrow$ CREATENEW LIST & [?] \\
\hline 1 & $B D B$ & 5creditcard.com & $A B C$ & \multicolumn{2}{|c|}{ more cash if you had have gone with an alternative bank credit cards. \# Look out for late expenses, such as a charge billed for rarely us } \\
\hline 2 & $B D B$ & banglabox.com & $A B C$ & \multicolumn{2}{|c|}{ Ultimately, you should trust your instincts. \# You must also be on the look out for combinations of these cheating signs for a more defin } \\
\hline 3 & $B D B$ & blog,globalmojo.com & $A B C$ & \multicolumn{2}{|c|}{ comes to Townhall140, it is safe to say we can all be on the look out for Townhall140 Version 2.0, as Liu tweeted yesterday, " Lining up a } \\
\hline 4 & $B D B$ & financeeasy.info & $A B C$ & \multicolumn{2}{|c|}{ a famous television host, Mr. Savile recounted, a police officer asked him to look out for a young girl who had run away from a home fo } \\
\hline 5 & $B D B$ & hasin.me & $A B C$ & \multicolumn{2}{|c|}{ download. \# Can anyone advice how to do it? or what i should look out for on firebug? \# Do you have a spam problem on this website } \\
\hline 6 & $B D B$ & nursingjobshome.com & $A B C$ & \multicolumn{2}{|c|}{ to get as much information as you can, as well as nursing forums. Look out for opportunities for nursing jobs in California 50 as to mak } \\
\hline 7 & $B D B$ & qafun.vabalu.com & $A B C$ & \multicolumn{2}{|c|}{ is likely to spend a lot of time playing, it is always advisable to look out for a pair of shoes or boots that fit well and protect the feet } \\
\hline 8 & $B D B$ & seudolab.com & $A B C$ & \multicolumn{2}{|c|}{ With that in mind, here are the top 10 qualities that most men usually look out for. It's in no particular order, as it differs from person } \\
\hline 9 & $B D B$ & bangladeshmlm.com & $A B C$ & \multicolumn{2}{|c|}{ decisions easier, "\#? Anyone who is unsure about what they need to look out for before buying a money product should visit our site f } \\
\hline 10 & $O B D B$ & bracu.ac.bd & $A B C$ & \multicolumn{2}{|c|}{ be futile to dedicate each of us in dealing with a grain of sand to look out for any discrepancy in the desert, since no grain of sand is diff } \\
\hline
\end{tabular}

Figure 4.8 First ten hits of look out for in BD English in the blog section

The senses of look out for are mostly to be vigilant and to search for something. However, as BD has far less data on the phrase look out for than the other three countries, it cannot be concluded whether the senses are used only in personal blogs and educational websites.

Table 4.4 Raw frequency and normalized frequency (NF) of put up with in the blog section of the GloWbE corpus
The third verb-preposition combination that I examined in GloWbE corpus is put up with. Table 4.4 on the following page shows that put up with is most frequent in GB English than the other three countries. The highest normalized frequencies are in GB (2.41), and the US (2.17) with the most hits, and the lowest is in BD (0.61) and IN (0.72).

\begin{tabular}{|c|c|c|c|c|c|}
\hline Section & $\begin{array}{c}\text { Total in } 20 \\
\text { Countries }\end{array}$ & US & GB & IN & $\mathrm{BD}$ \\
\hline Frequency (raw) & 3181 & 839 & 934 & 69 & 24 \\
\hline Words (M) & 1900 & 386.8 & 387.6 & 96.4 & 39.5 \\
\hline Per Million (NF) & 1.67 & 2.17 & 2.41 & 0.72 & 0.61 \\
\hline
\end{tabular}


The chart function in GloWbE shows that put up with was mostly used in personal blogs in the US data. The first ten hits in US English (figure 4.9) shows that the prepositional verb put up with was used to mean 'to tolerate' or 'to endure' (WordNet Search - 3.1) in all the cases.

\begin{tabular}{|c|c|c|c|c|c|c|c|}
\hline \multicolumn{8}{|c|}{$\begin{array}{l}\text { SECTION: United States (839) } \\
\text { FIND SAMPLE: } 100 \underline{200} \underline{500} \\
\text { PAGE: } \ll<1 / 9\rangle \gg\end{array}$} \\
\hline \multicolumn{5}{|c|}{ CLICK FOR MORE CONTEXT } & $\square$ [?] & SAVE LIST CHOOSE LIST $\cdots$ CREATE NEW LIST & [?] \\
\hline 1 & USB & 100rsns.blogspot.com & A B & $C$ & \multicolumn{3}{|c|}{ the top $15 \%$ of all earners and that's a different ballgame. I would put up with a job I didn't much like to make 6 figures, knowing } \\
\hline 2 & USB & ....rs.pressdemocraticom & $A B$ & $\mathrm{C}$ & \multicolumn{3}{|c|}{ do. \# How many more freaking weeks of Alex Smith are we going to put up with when we know that he's not going to get us where we } \\
\hline 3 & USB & aaroncollins.org & $A B$ & $C$ & \multicolumn{3}{|c|}{ it is a disgrace to our men and women who earn $\$ 2.00$ an hour to put up with rude customers or even customers in general and what Aaron } \\
\hline 4 & USB & add-vodka.com & $A B$ & C & \multicolumn{3}{|c|}{, which I feel when I'm in the office. \# If you can put up with somebody outside the workplace, there's a chance you'll get along } \\
\hline 5 & USB & agonist.org & A B & $\mathrm{C}$ & \multicolumn{3}{|c|}{ countries know they canTt win a war against the US, so they have to put up with it. Nonetheless, drone attacks are clear violations of interna } \\
\hline 6 & USB & alfonzorachel.com & A B & C & \multicolumn{3}{|c|}{ Mitt's a good man, and I actually find it amazing that anyone would put up with the crap the MSM and political wonks throw at anyone runni } \\
\hline 7 & USB & ...maknack.blogspot.com & A B & C & \multicolumn{3}{|c|}{ in my life other than to boost my ego when V wasn't willing to put up with my shenanigans. Needless to say I deleted his number shortly afte } \\
\hline 8 & USB & ...lthouse.blogspot.com & $A B$ & C & \multicolumn{3}{|c|}{100 reasons. I just got the MA for enrichment, so I didn't put up with the rite of passage torture that my adviser doled out. I ca } \\
\hline 9 & USB & ...lthouse.blogspot.com & A B & C & \multicolumn{3}{|c|}{, like, out of the blue) and made an insulting film. We put up with freaking Fred Phelps and a bunch of hot-heads on the other side of } \\
\hline 10 & USB & ...lthouse.blogspot.com & A B & & \multicolumn{3}{|c|}{.\# Funny to think Bill Ayers and others were the douchebags he had to put up with at Columbia in the late 60 s. You can see how he might } \\
\hline
\end{tabular}

Figure 4.9 First ten hits of put up with in US English in the blog section

As GB has the highest raw frequency (934) of put up with among the four countries, the first ten instances (figure 4.10) are from personal blogs, and the collocating words nearby the phrase put up with were primarily used in negative senses, for example, in hit 2, “... put up with all the other crap ...", and in hit 5, "... put up with all the insults..." to show the meaning 'to put up with something or somebody unpleasant' (WordNet Search - 3.1).

\begin{tabular}{|c|c|c|c|c|c|}
\hline \multicolumn{6}{|c|}{$\begin{array}{l}\text { SECTION: Great Britain (934) } \\
\text { FIND SAMPLE: } 100 \underline{200} \underline{500} \\
\text { PAGE: } \ll\langle 1 / 10\rangle \gg\end{array}$} \\
\hline \multicolumn{3}{|c|}{ CLICK FOR MORE CONTEXT } & $\square$ [?] & SAVE LIST CHOOSE LIST $\ldots$ CREATENEW LIST & [?] \\
\hline 1 & GBB & ...differentangle.co.uk & $A B C$ & \multicolumn{2}{|c|}{ sorted out, I don't know how much longer I will be able to put up with it. " \# " What are you saying? " \# " } \\
\hline 2 & GBB & ...differentangle.co.uk & $A B C$ & \multicolumn{2}{|c|}{." This, Paula... I can't take it anymore. I can put up with all the other crap, your mood swings, the debt but when } \\
\hline 3 & GB B & ...friend.wordpress.com & $A B C$ & \multicolumn{2}{|c|}{, I'm at the stage where I wonder whether anyone would be able to put up with a' post-crisis-Puffles' -Bestest-Buddy.' At the moment } \\
\hline 4 & GBB & ...fitness.blogspot.com & $A B C$ & \multicolumn{2}{|c|}{ this year! Much discussion and analysis followed, thanks to everyone who has to put up with me, you are stars!! I think I can see the } \\
\hline 5 & GB B & alexinleeds.com & $A B C$ & \multicolumn{2}{|c|}{ \# Collins' long term partner Caroline loved him, acted nursemaid to him and put up with all the insults society gave her for living with } \\
\hline 6 & GB B & ....jahom.wordpress.com & $A B C$ & \multicolumn{2}{|c|}{, been told I had 24 hrs to leave HIS house if I wouldn't put up with his over active sex drive, pack the car, load up the } \\
\hline 7 & GB B & ...roundus.blogspoticom & $A B C$ & \multicolumn{2}{|c|}{ in boxes. \# If it was just my little part time hobby I'd put up with it, and thank my lucky stars I had any space at all } \\
\hline 8 & GB B & angryofislington.com & $A B C$ & \multicolumn{2}{|c|}{ club needs change from the top down......... otherwise just sit back shut up and put up with Wenger and these average players, being } \\
\hline 9 & GB B & ...kers,boroblogs.co.uk & $A B C$ & \multicolumn{2}{|c|}{ it was a step too far. \# As Boro fans we have had to put up with years of vile taunting over the child abuse scandal at the hands of } \\
\hline 10 & GB B & ...kers.boroblogs.co.uk & $A B C$ & \multicolumn{2}{|c|}{ disaster. \# Manchester fans referring similarly to Hillsborough. \# Spurs fans having to put up with Jewish cracks. \# Elderly managers ( } \\
\hline
\end{tabular}

Figure 4.10 First ten hits of put up with in GB English in the blog section

India has 69 examples of put up with in the blog (figure 4.11). section, out of which I looked into the first ten hits 


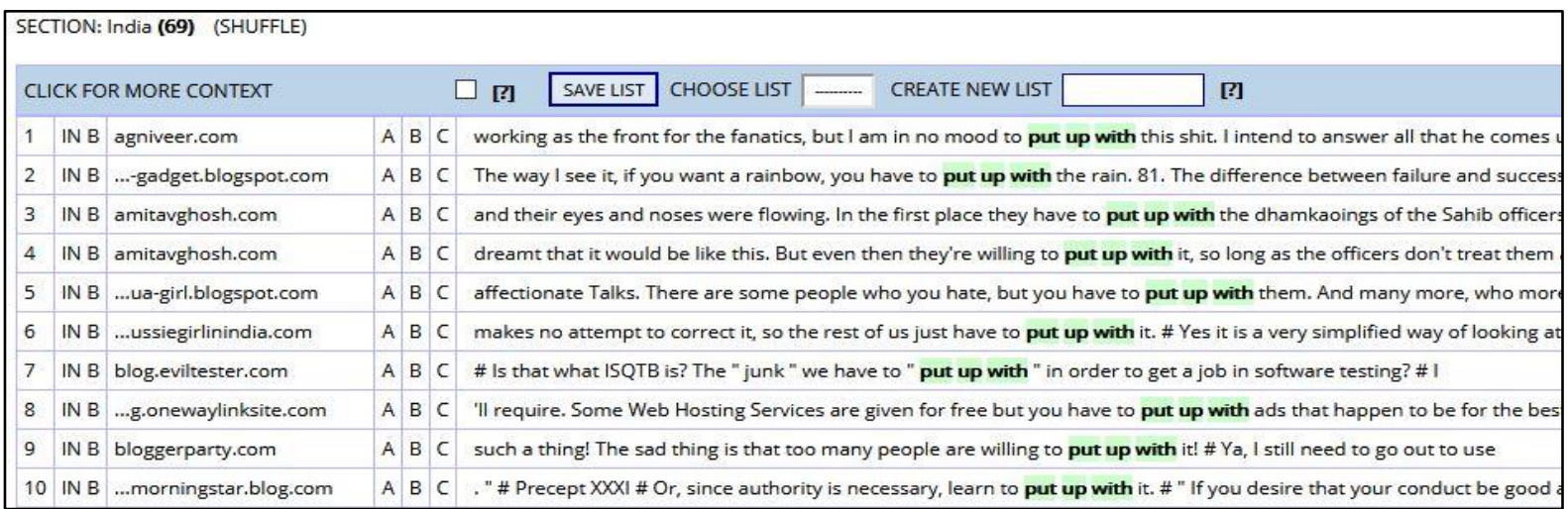

Figure 4.11 First ten hits of put up with in IN English in the blog section

The examples show that the phrase put up with was used in negative contexts in the personal blogs. For example, hit 1, "... put up with this shit." and in hit 5, "There are some people whom you hate, but you have to put up with them", all indicate the sense 'to tolerate'. In BD English, the raw frequency was only 24 in the blog section. The first ten examples using the chart function in GloWbE corpus (figure 4.12) shows the usage of put up with in informal blogs.

\footnotetext{
SECTION: Bangladesh (24) (SHUFFLE)

CLICK FOR MORE CONTEXT $\quad \square$ [? $\quad$ SAVE LIST CHOOSE LIST $\square$ CREATE NEW LIST $\square$ [?]

1 BD B ...shoes.wefoundsky.com A B $\quad$ C to provide a lung after september even the particular Lv Socket fundamental for you to put up with In, turns into easy

2 BD B anushayspoint.com $\quad$ A B C was a machine. And I got passed around to so many men and simply put up with their rape and sodomy. When I coulc

3 BD B ...travelz.blogspot.com $\quad$ A $B$ B $C$ also because he made it absolutely clear that unlike the previous nawabs he would not put up with the abuse of dasta

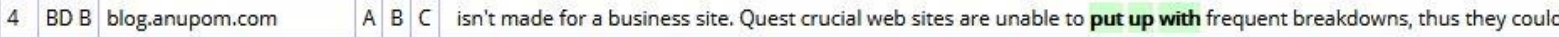

5 BD B ...hhomebd.blogspot.com A B C . The earth for us is a place to live in, where we must put up with sights, with sounds, with smells too, by Jove! -

6 BD B ...um.banglalibrary.org $\quad$ A B C the material, and imitating the ways of the world. He was unwilling to put up with the discomforts of heat and cold, th

7 BD B ...ashedin.blogspot.com A B C , shouldn't we have Shariah laws controlling our lives as Muslims? Can we put up with Shariah laws as a nation which

8 BD B bdtvstar.com $\quad$ A B C does not have to wait to have her items scanned and does not have to put up with the children asking if they can have

9 BD B ben-center.org $\quad$ A B C posh venue accords well with that principle. Similarly, many foreign guests will be put up with families of environment

10 BD B ...tom-rugs-carpets.com A $\quad$ B C inverse roll up, remember not to try to do things the easy way to put up with setbacks and hard ground, custom rugs t
}

Figure 4.12 First ten hits of put up with in BD English in the blog section

BD English also shows the negative usage of put up with in the first ten instances. For example, in hit 2, "... put up with their rape and sodomy...", and in hit 3 , “... put up with the abuse ...".
The fourth verb-preposition combination in my investigation list is stand up. Table 4.5 shows that; the raw frequency is the highest in the US among the four countries in the blog section of the GloWbE corpus.

Table 4.5 Raw frequency and normalized frequency (NF) of stand up to in the blog section of the GloWbE corpus

\begin{tabular}{crrrrr}
\hline \multicolumn{1}{l}{ Section } & Total in 20 countries & US & GB & IN & \multicolumn{2}{c}{ BD } \\
\hline Frequency (raw) & 2188 & 615 & 571 & 58 & 20 \\
Words (M) & 1900 & 386.8 & 387.6 & 96.4 & 39.5 \\
Per Million (NF) & 1.15 & 1.59 & 1.47 & 0.60 & 0.51
\end{tabular}


It also shows that the inner-circle countries, e.g. US and GB have more data than the outer-circle countries, e.g. IN and BD. If I investigate the data using the chart function of the GloWbE corpus, I see that the first ten hits in US English (figure 4.13) shows that the phrase stands up to have been used in political contexts the personal blog writers. There are
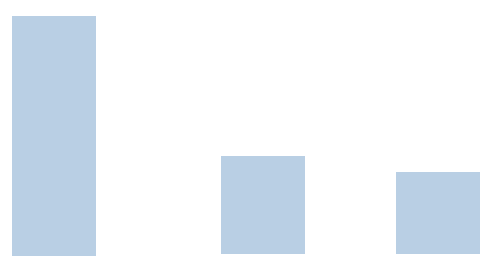

seven senses of stand up in the WordNet Search - 3.1. However, in US data, the meaning 'defend against' or 'resist' have been used, for example, in hit 1, "... stand up to EVIL ...", and in hit 2, “... stand up to the Taliban...", the meaning 'defend against or 'resist' is appropriate.

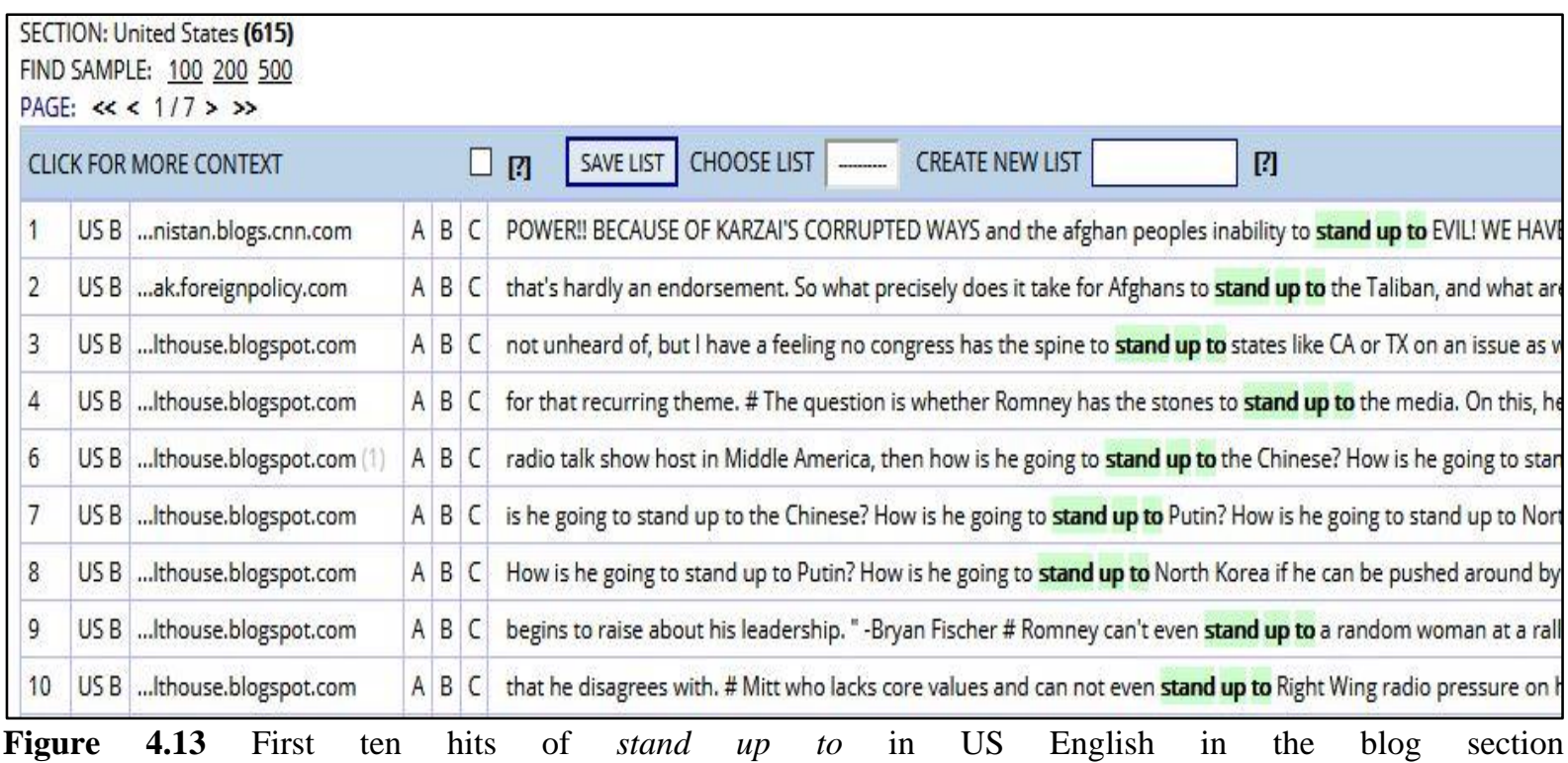

If I look into the GB data for the phrase stand up to, the first ten hits using the chart function give in Figure 4.14. The examples show that British English is much more variant than the American one. Although the examples are from informal blogs, the contexts vary from politics to sports to personal experiences. However, the meaning sense is mostly 'to defend' or 'to resist'. For example, in hit 1, “... stand up to these greedy ...", and in hit 2, “... stand up to these money-hungry..." shows the negative context of the phrase stand up to. 


\begin{tabular}{|c|c|c|c|c|c|c|c|}
\hline \multicolumn{8}{|c|}{$\begin{array}{l}\text { SECTION: Great Britain (571) } \\
\text { FIND SAMPLE: } \underline{100} \underline{200} \underline{500} \\
\text { PAGE: } \ll\langle 1 / 6\rangle \gg\end{array}$} \\
\hline \multicolumn{4}{|c|}{ CLICK FOR MORE CONTEXT } & \multicolumn{2}{|c|}{$\square$ [?] } & SAVE LIST CHOOSE LIST $-{ }_{-}$CREATE NEW LIST & [?] \\
\hline 1 & GB B & 4liberty.org.uk & A $B$ & $C$ & \multicolumn{3}{|c|}{ blaming everyone but themselves. \# What we need is a strong government that can stand up to these greedy vultu } \\
\hline 2 & GB B & 4liberty.org.uk & $A B$ & 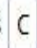 & \multicolumn{3}{|c|}{ makes my blood boil. \# Again, we need a strong government that can stand up to these money-hungry, power-hun } \\
\hline 3 & GB B & acommonreader.org & A $B$ & $C$ & \multicolumn{3}{|c|}{ cover replicating the first edition published in 1929 . I wondered how the book would stand up to the passage of tim } \\
\hline 4 & GB B & ...friend.wordpress.com & $A B$ & C & \multicolumn{3}{|c|}{ this era of cuts, civil servants and ministers have to be brave enough to stand up to the Treasury and demand an in } \\
\hline 5 & GB B & ...andragoldstein.co.uk & A B & $\mathrm{c}$ & \multicolumn{3}{|c|}{ - since salmon is so rich and oily, but it's meaty enough to stand up to more indulgent treatment if you want to pus } \\
\hline 6 & GB B & alexinleeds.com & $A B$ & $C$ & \multicolumn{3}{|c|}{ multitude of plots and sub-plots can make up the absence. It just doesn't stand up to close on 700 pages of scrutiny } \\
\hline 7 & GB B & arseblog.com & A $B$ & $C$ & \multicolumn{3}{|c|}{ pre AGM groundwork, but there's no doubt some parts of it don't stand up to too much examination, even if you're } \\
\hline 8 & GB B & ...ruth.squarespace.com & $A B$ & $\mathrm{C}$ & \multicolumn{3}{|c|}{ to add that kroenke and gazdis are hiding behind the FFP, it will never stand up to anything. MCFC Eithad project ar } \\
\hline 9 & GBB & ...ologist.blogspot.com & $A B$ & $C$ & \multicolumn{3}{|c|}{ remarks made on his blog. Tony doubted the Tory PCC candidate for Staffordshire would stand up to the fascists in } \\
\hline 10 & GB B & ba-flights.co.uk & $A B$ & $\mathrm{C}$ & \multicolumn{3}{|c|}{ Relationship? " \# he is not a real man he needs to learn to stand up to his family and say look i want to be with this } \\
\hline
\end{tabular}

Figure 4.14 First ten hits of stand up to in GB English in the blog section

The first ten hits out of 58 raw data from Indian English in the blog section show that the context varies

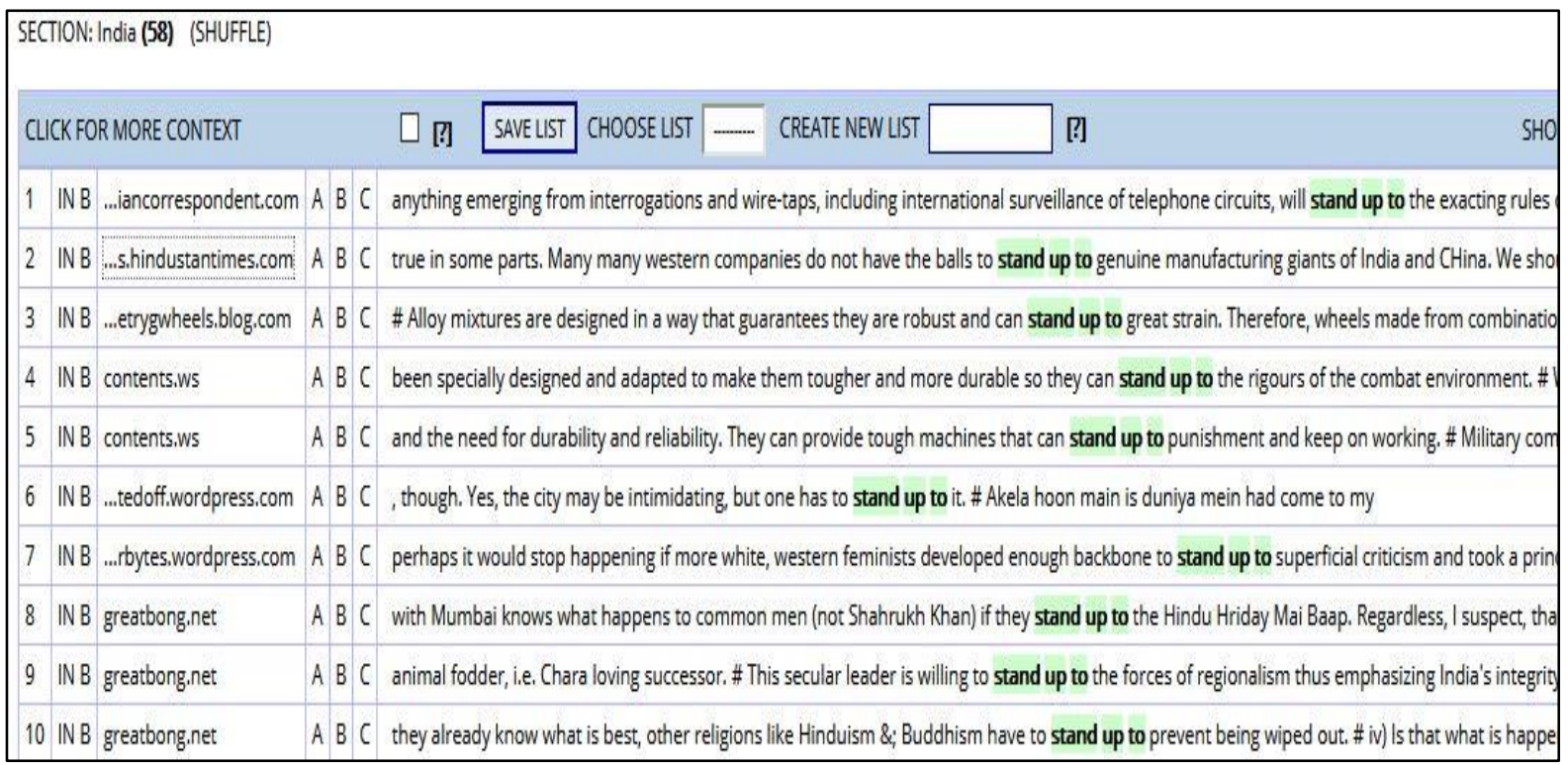

Figure 4.15 First ten hits of stand up to in IN English in the blog section

The examples are personal blogs, blogs related to movies and songs, newspaper blogs and business blogs. Here, the meaning sense of stand up to is mostly 'to defend against'. For example, in hit 3, “... stand up to great strain ...", and in hit 5, "... stand up to punishment ..." shows the variety of usage in Indian English.
BD English has only 20 raw data, and I checked the first ten out of those (figure 4.16). Examples indicate stand up was used in websites and personal blogs related to technology, mobile phones and vehicles, and also in one of the newspaper articles. For example, in the first hit, the sample was from a technology blog and in the tenth hit, the sample was from a newspaper website. 
ISSN (Online): 2685-3906, ISSN (Print): 2685-0818

DOI: https://doi.org/10.31849/reila.6108

Vol. 3, No. 1, April, 2021, pp. 26-41

\begin{tabular}{|c|c|c|c|c|c|c|c|}
\hline \multicolumn{8}{|c|}{ SECTION: Bangladesh (20) (SHUFFLE) } \\
\hline \multicolumn{5}{|c|}{ CLICK FOR MORE CONTEXT } & $\square$ [?] & SAVE LIST CHOOSE LIST $\longrightarrow$ CREATE NEW LIST & [?] \\
\hline 1 & BD B & androidproapps.com & A B & & \multicolumn{3}{|c|}{ today would be nothing without Android, which was a base to lean on to stand up to the iPhone and Nokias that don } \\
\hline 2 & BD B & bdinn.com & A B & $B C$ & \multicolumn{3}{|c|}{ of its army and to strengthen the political leadership of Pakistan and enable it to stand up to the Army. \# If this was } \\
\hline 3 & BD B & ...hhomebd.blogspot.com & $A B$ & $B C$ & \multicolumn{3}{|c|}{, patience, fear - or some kind of primitive honor? No fear can stand up to hunger, no patience can wear it out, disgy } \\
\hline 4 & BD B & hackread.com & A B & $B C$ & \multicolumn{3}{|c|}{ have done nothing but hurt and kill our innocent people! It is time we stand up to you, NATO, and show you that we } \\
\hline 5 & $B D B$ & ...e-carpet-reviews.com & A B & $B C$ & \multicolumn{3}{|c|}{ Carpets made of recycled materials on the other hand, are usually much tougher and stand up to stains and wear an } \\
\hline 6 & $B D B$ & ...easfortechnology.com & A B & $B C$ & \multicolumn{3}{|c|}{ accessories like saddles and a waterproof housing (included as standard). Will it stand up to the successful GoPro? } \\
\hline 7 & $B D B$ & ...yclebuyersguide.info & A B & $B C$ & \multicolumn{3}{|c|}{ braking, the fork ( $+3 \mathrm{~mm}$ in diameter) is better able to stand up to high decelerations. On the other hand, the shock } \\
\hline 8 & $B D B$ & mukto-mona.com & A $B$ & $B C$ & \multicolumn{3}{|c|}{ (4346) - " Was not there a wise man among you who would stand up to him when he saw that I had withheld my har } \\
\hline 9 & $B D B$ & newsflavor.com & $A B$ & $B C$ & \multicolumn{3}{|c|}{ provoking a war with their recent actions. Their actions confirrn their radicalized ideas. Stand up to these bully's } \\
\hline 10 & $B D B$ & opinion.bdnews24.com & A B & $B C$ & \multicolumn{3}{|c|}{ and evaluated accordingly, not as a businessman or a successful entrepreneur. Does he stand up to the scrutiny? \# } \\
\hline
\end{tabular}

Figure 4.16 First ten hits of stand up to in BD English in the blog section

The fifth verb-preposition combination I looked into GloWbE is get along with. Table 4.6 shows the frequency of get along with in four countries. The raw frequency is high in the US and GB (237 and 143 respectively) and low in IN and BD (44 and 18 respectively). However, the normalized frequency in GB (0.37) is lower than the frequencies of the US (0.61), IN (0.46) and BD (0.46).

Table 4.6 Raw frequency and normalized frequency (NF) of get along with in the blog section of the GloWbE corpus

\begin{tabular}{cccccc}
\hline Section & Total in 20 countries & US & GB & IN & BD \\
\hline Frequency (raw) & 881 & 237 & 143 & 44 & 18 \\
Words (M) & 1900 & 386.8 & 387.6 & 96.4 & 39.5 \\
Per Million (NF) & 0.46 & 0.61 & 0.37 & 0.46 & 0.46
\end{tabular}

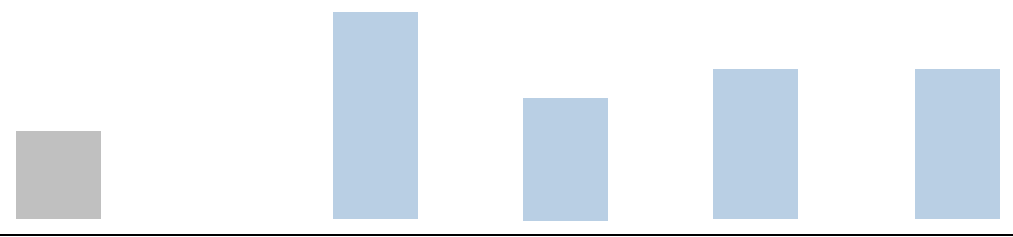

Like the previous data collection, I used the chart function to get the first ten hits of get along with in the US English. Figure 4.17 shows the result. In this regard, it is to be mentioned, WordNet Search - 3.1 shows 'have smooth relations' as the meaning of get along

with. 


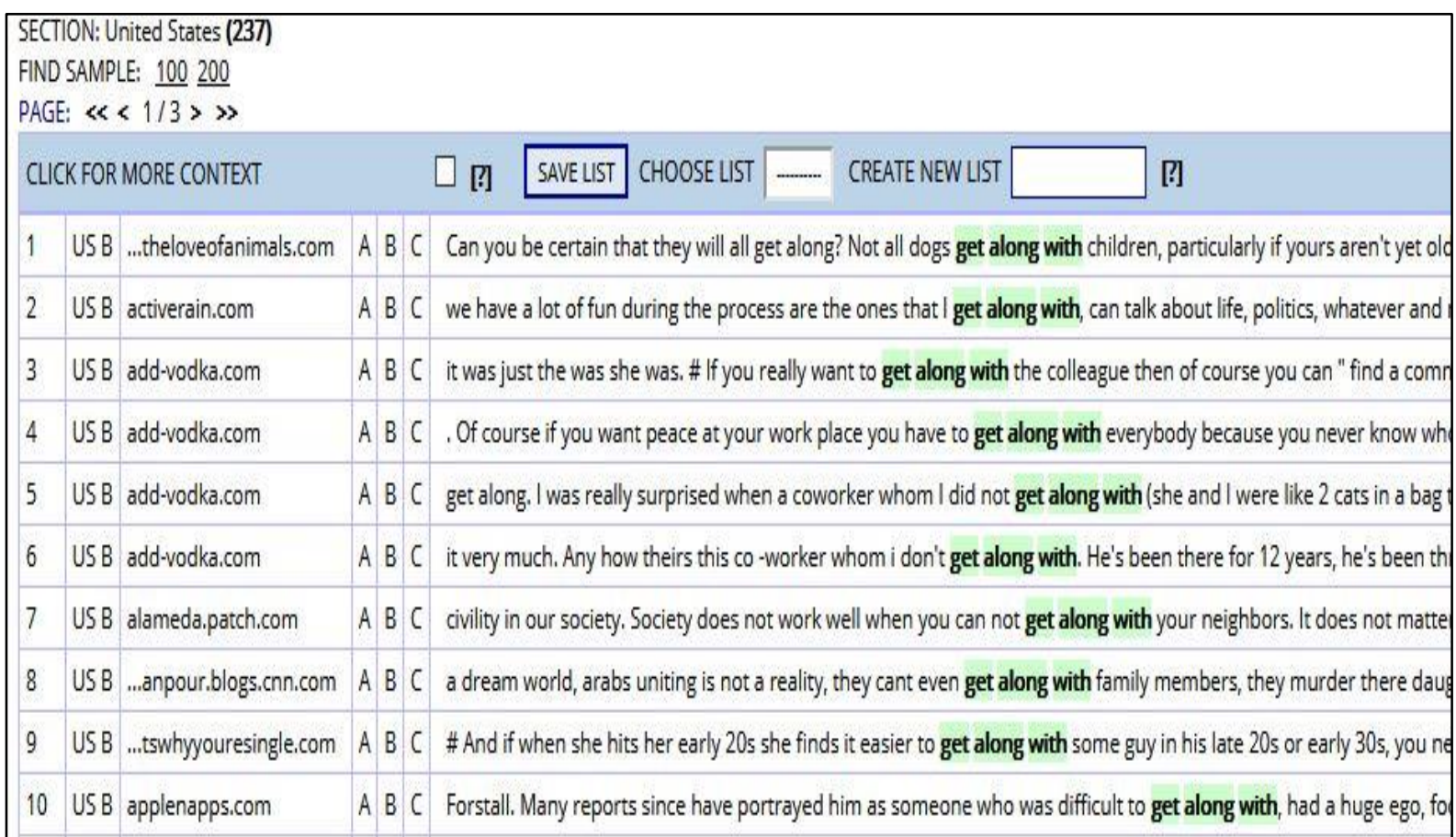

Figure 4.17 First ten hits of get along with in US English in the blog section

Figure 4.17 shows the usage of get along with in social contexts in US English. Here, all the examples depict the meaning 'have smooth relations' with someone or something, from their society or a workplace. If I look at the GB data (figure 4.18), it shows the usage in social and religious contexts in the blog section.

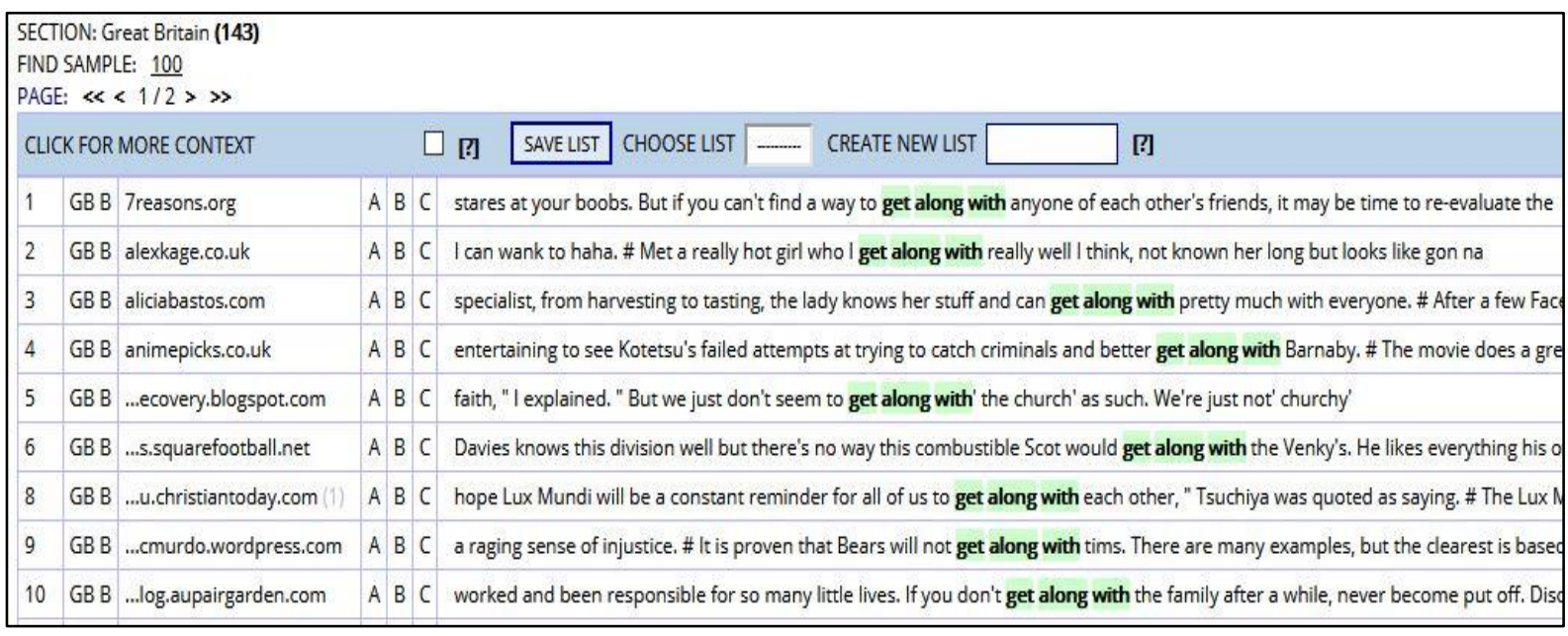

Figure 4.18 First ten hits of get along with in GB English in the blog section

In Indian English, I noticed from figure 4.19 that get along with was used in the blogs discussing social life and movies. The sense is similar to the other three countries. 


\begin{tabular}{|c|c|c|c|c|c|c|}
\hline \multicolumn{7}{|c|}{ SECTION: India (44) (SHUFFLE) } \\
\hline \multicolumn{5}{|c|}{ CLICK FOR MORE CONTEXT } & $\square$ [?] SAVE LIST CHOOSE LIST $\square$ CREATE NEW LIST & [?] \\
\hline 1 & IN B & 007dossier.com & A B & & .\#" By then, even Jack was finding it very difficult to get along wi & as subsequently brought back in by Kersh for more rewriti \\
\hline 2 & IN B & apptha.com & A B & & decide on it. \# Listed down are some of the general features that & th this pop up extension: \# 1. Multiple Feedback Pop up c \\
\hline 3 & IN B & ...ua-girl.blogspot.com & A B & $B c$ & their past to set their future right, and how they help each other & th life forms the rest of the story. \# This book stands apart \\
\hline 4 & IN B & blog.simplilearn.com & A B & $B C$ & all important but that is not the case, the important factor is to $g$ & a team, with people, to be able to drop your ego. \\
\hline 5 & IN B & ...logs.dotnetkicks.com & A B & B C & , Or in case of good, Hardly had he spoken, although you get alor & oot much time, Look forward to the addition of several for \\
\hline 6 & IN B & centreright.in & A B & $B C$ & ?... just shut up, and mind your own business. Let me get along $\mathrm{w}$ & " There were a couple of passers-by who watched this and \\
\hline 7 & IN B & cineplot.com & A B & $B C$ & in an actor whom people like to think of as one nobody can ever & th. \# " Bulundi " in which Raaj Kumar's college professor w \\
\hline 8 & IN B & expertscolumn.com & A B & $B C$ & very few real friends out there. We have plenty of people who we & ith but for some reason, those individuals do not cross tha \\
\hline 9 & IN B & fsl-india.org & A B & $B C$ & Paper production " and lots more. \# Some children who learn eas & long with how they learn startled us with their ability to $\mathrm{sh}$ \\
\hline 10 & IN B & girisopinion.me & A B & & Olympics, Davis Cup etc... So it does not require the players to ge & each other like how it is with other team sports. The playe \\
\hline
\end{tabular}

Figure 4.19 First ten hits of get along with in IN English in the blog section

When looked into BD English (figure 4.20), I found that the first ten hits with get along with were used in political blogs, online news portals and

personal blogs with the meaning sense 'to have smooth relations'.

\begin{tabular}{|c|c|c|c|c|}
\hline \multicolumn{5}{|c|}{ SECTION: Bangladesh (18) (SHUFFLE) } \\
\hline \multicolumn{3}{|c|}{ CLICK FOR MORE CONTEXT } & SAVE LIST CHOOSE LIST $\longrightarrow$ CREATENEW LIST & SHOW DUF \\
\hline 1 & BD B aagghs.edu.bd & $A B C$ & \multicolumn{2}{|c|}{ different types. For example, they may include a student's failure to get along with peers, delinquent in activities, excessive withdrawal as well as disrup } \\
\hline 2 & BD B ....blacktigergroup.com & $A B C$ & \multicolumn{2}{|c|}{ Just keep caring about them and doing what is good for them. \# GET ALONG WTH THE OTHER PARENT. This, of course, is not entirely in your } \\
\hline 3 & BD B ...lochona.blogspot.com & $A B C$ & \multicolumn{2}{|c|}{ demon first before you go after other hearts. \# These people need to get along with their Burmese counterparts and integrate into that society rather t } \\
\hline 5 & BD B earnbyblog,com (1) & $A B C$ & \multicolumn{2}{|c|}{ I know a strategy. Make use of the off -topic thread and get along with other forum members. Then eventually you can start the things mentioned abov } \\
\hline 7 & BD B ekush.wordpress.com & $A B C$ & \multicolumn{2}{|c|}{ Aung San Suu Kyi last week urged "all people in Burma to get along with each other regardless of their religion and authenticity. "But she has remaine } \\
\hline 8 & BD B nazzina.com & $A B C$ & \multicolumn{2}{|c|}{ say its hard to blend yourself in a new school but its harder to get along with affluent classmates especially when you are not one of them! To make ma } \\
\hline 9 & BD B adhunika.org & $A B C$ & \multicolumn{2}{|c|}{ at their jobs? Do they feel pressured to behave a certain way to get along with their co-workers (for example, going out for drinks after work)? } \\
\hline & BD B bdnewslive,com & $A B C$ & \multicolumn{2}{|c|}{ trouble if the incumbent wins. \# "If our prime minister doesn't get along with their leader, it will hurt our relations, " said Shai Hugi, } \\
\hline
\end{tabular}

Figure 4.20 First ten hits of get along with in BD English in the blog section.

\section{Discussion}

In the previous section, I collected data for the five prepositional verbs - come up with, look out for, put up with, stand up to, and get along with from the 'only blogs' segment of the GloWbE corpus and analyzed those data with related examples to show the variation in results. From the data, it is evident that, in all the cases, the US and GB have more data, i.e. raw frequency of the five verb-preposition combinations, than IN and BD. There may be many reasons for this. For example - Great Britain has a long history of colonization in the US, and later, in the Indian subcontinent. Kachru (cf. 1985, p.12) points out that the spread of English happened because of the "extended periods of colonization, essentially by the users of the inner circle varieties". Thus, the US and GB have a larger corpus of web data than the outercircle countries - India and Bangladesh. Another reason, perhaps, is that India received independence later in 1947 and Bangladesh in 1971, both countries with different native tongues; thus, English did not have the privilege of being the primary language. Moreover, in the case of Bangladesh, Bengali linguistic identity was the primary catalyst to receive independence (cf. Kabir 1987, p.482-484).

In the case of collocations, I found that some verbpreposition combinations are used in some specific contexts. For example, come up with in US data (first ten hits) mainly was used for political contexts, whereas, come up with in Indian English (first ten hits) was mostly used in the festival and cultural contexts. Furthermore, some phrases are exclusively used in negative contexts; for example, put up with in all the four countries, was used in most negative situations when someone has to tolerate something reluctantly. In the case of stand up to, this phrasal verb is also used in political contexts in the US data, 
while it has multiple usage contexts in GB data, unlike the US.

The research explores the GloWbE database on the prepositional verbs extensively and illustrates the usage in individual countries. As prepositional verbs are part and parcel of everyday conversations, the informal usage with examples shows the trending topics of discussion in the websites in those specific countries. However, future research can improve a similar topic by adding more English speaking countries and, subsequently, adding more data or examples from the corpus. Comparisons can be made with other corpora such as British National Corpus (BNC) etc. Future researches can also show the usage in the general section from the GloWbE corpus to find exciting outcomes.

To the end of the discussion, it can be said that, in the 'only blogs' section of the GloWbE corpus, the five verb-prepositions are used in numerous contexts, and their meanings vary depending on the country, type of socio-political situation, type of culture and also on the type of blog, newspaper, magazine or business company web sites.

\section{Conclusion}

English has a broad spectrum of domains in which it is used with varying degrees of competence by members of society, both as an intranational and an international language (Kachru 1985, p. 12). To sum up, it can be said that my assumptions in the introduction were appropriate, as there were more data in the US and GB English compared to the IN and $\mathrm{BD}$, and, also, the five verb-preposition combinations were used in varied contexts in those countries. Although some verbs were in low frequency yet, the fact illustrates less use of those verbs, particularly in the outer-circle countries, which perhaps justifies Liao and Fukuya's (cf. 2004, p. 194) concept that the second language learners of English try to avoid using phrasal verbs. From the corpus data, it was also clear that the verb-preposition combinations vary in their frequency and, to some extent, in meaning in the four countries. However, as the GloWbE has web data from only the years 2012 and 2013, it can be depicted as the limitation of the study. Perhaps, if the corpus had more data ranging from other periods, I could have found more frequency and more variations among the countries.

\section{References}

Baldwin, T. (2005). Looking for prepositional verbs in corpus data. In Proc. of the Second ACLSIGSEM Workshop on the linguistic dimensions of prepositions and their use in computational linguistics formalisms and applications, Colchester, UK, 115-126.

Cambridge Dictionary online. Definition of run up against something/someone. (2021). Cambridge University

Press. https://dictionary.cambridge.org/dictionary/englis $\mathrm{h}$ /run-up-against-something-someone accessed on 05 Jan. 2021.

Dagut, M., \& Laufer, B. (1985). Avoidance of phrasal verbs-A case for contrastive analysis. Studies in Second Language Acquisition, 7(1), 73-79. https://doi.org/10.1017/s0272263100005167

Davies, M. (2013). Corpus of Global Web-Based English: 1.9 billion words from speakers in 20 countries (GloWbE). Available online at https://corpus.byu.edu/glowbe/.

Davies, M. (2015). "Introducing the 1.9 Billion Word Global Web-Based English Corpus (GloWbE)". The 21st Century Text (Peer-reviewed, online journal).https://21 centurytext.wordpress.com/intr oducing-the-1-9-billion-word-global-web-basedenglish-corpus-glowbel accessed on 23 Nov. 2020.

Davies, M. (2020). English-Corpora.org: A guided tour. Available online at www.englishcorpora.org > pdf > english-corpora. Accessed on 12 Nov. 2020.

Davies, M., \& Fuchs, R. (2015). Expanding horizons in the study of World Englishes with the 1.9 billion word Global Web-based English Corpus (GloWbE). English World-Wide, 36(1), 1-28. Crossref, doi:10.1075/eww.36.1.01dav.

Gardner, D., and Davies, M. (2007). Pointing Out Frequent Phrasal Verbs: A Corpus-Based Analysis. TESOL Quarterly, 41(2), 339-359. https://doi.org/10.1002/j.15457249.2007.tb00062.x

Huddleston, R. D., \& Pullum, G. K. (2002). The Cambridge Grammar of the English Language. Cambridge: Cambridge University Press.

Iabdounane, Y. (2020). Sociolinguistics and Corpus Linguistics - Compare a language across different regions and speakers. https://www.youtube.com/watch?v=9s7cJY8EIr, Video from 4:20 minutes. Accessed on 02 Dec. 2020.

Kabir, M. G. (1987). Religion, language and nationalism in Bangladesh. Journal of contemporary Asia, 17(4), 473-487. 
ISSN (Online): 2685-3906, ISSN (Print): 2685-0818

DOI: https://doi.org/10.31849/reila.6108

Vol. 3, No. 1, April, 2021, pp. 26-41

Kachru, B. B. (1985). Standards, codification and sociolinguistic realism: The English language in the outer circle. na.

Kennedy, G. (1998). An Introduction to Corpus Linguistics. $1^{\text {st }}$ edition. New York: Addison Wesley Longman Inc.

Krug, M., and Schlueter, J. (2013). Research Methods in Language Variation and Change. New York: Cambridge University Press.

Liao, Y., \& Fukuya, Y. J. (2004). Avoidance of Phrasal Verbs: The Case of Chinese Learners of English. Language Learning, 54(2), 193-226. doi:10.1111/j.1467-9922.2004.00254.x

Liu, D. (2011). The Most Frequently Used English Phrasal Verbs in American and British English: A Multicorpus Examination. TESOL Quarterly, 45(4), 661-688. doi:10.5054/tq.2011.247707

McEnery, T., Hardie, A. \& Baker, P. (2006). A Glossary of Corpus Linguistics (Glossaries in Linguistics). Edinburgh: Edinburgh University Press.

Ostyn-Rudzka, B. (2003). Word power: Phrasal verbs and compounds a cognitive approach. Berlin: Mouton de Gruyter.

Princeton University "About WordNet." WordNet. (2010). Princeton University. http://wordnetweb.princeton.edu/perl/webwn?s=c ome + up \&sub $=$ Search + WordNet\&o $2=\& o 0=1 \& o 8$ $=1 \& 01=1 \& 07=\& 05=\& 09=\& 06=\& 03=\& 04=\& \mathrm{~h}=$ 